\title{
Study of changes in Surface Temperature of Facial Region due to Mobile Phone Radiation
}

\author{
C.R. Parvathy ${ }^{1 *}$,Meghna Hukeri ${ }^{2 *}$,Santhoshi N Krishnan ${ }^{3 *}$, Oinam Robita Chanu ${ }^{40}$, M. Anburajan ${ }^{5 \#}$ \\ Dept. of Biomedical Engineering \\ SRM University \\ Kattankulathur, India \\ oinamrobita.c@ktr.srmuniv.ac.in ${ }^{4}$ hod_biomedi@ktr.srmuniv.ac.in ${ }^{5}$ \\ $* 4^{\text {th }}$ year B.Tech -Biomedical Engineering, ${ }^{\mathrm{O}}$ Assistant Professor, ${ }^{\#}$ Professor and Head
}

\begin{abstract}
Mobile phones are radio devices that operate on less than 1 Watt and use Radio Frequency (RF) energy to emit microwave radiation. With the increasing use of mobile phones amongst the youth, there is also an added risk of exposure to harmful electromagnetic radiation. Rate of exposure of RF radiation to the body is measured using Specific Absorption Rate (SAR) unit and limit is set at $2.0 \mathrm{~W} / \mathrm{kg}$ averaging over 10 gram of tissue according to European Union (EU) standards. The aim and objective of the study is to assess the surface temperature increase in the ear region. This region was selected based on proximity to the standard position of mobile phones while talking. Infrared Thermal Imaging module and methods were used to determine the exposure to radiation. Mobile phones with SAR values of 0.41 and 1.4 Watts/kgwere used as test models. Eight subjects of the age group 18-23 were made to talk on the phone for duration of ten minutes with and without headset. Thermal images were obtained before and after radiation exposure and a comparative analysis was performed using FLIR Research IR software for the given cases. After statistical analysis, it was found that there was an increase in surface temperature of $0.4^{\circ} \mathrm{C}$ in the right ear as compared to the left earwhere a decrease of $0.1^{\circ} \mathrm{C}$ after radiation exposure was observed during direct contact, as compared to headset usage, where both regions show increase in temperature.
\end{abstract}

Keywords-Radio Frequency(RF); Ultra High Frequency(UHF) ;Specific Absorption Rate(SAR); Thermal Imaging; FLIR Research IR

Key image :

1

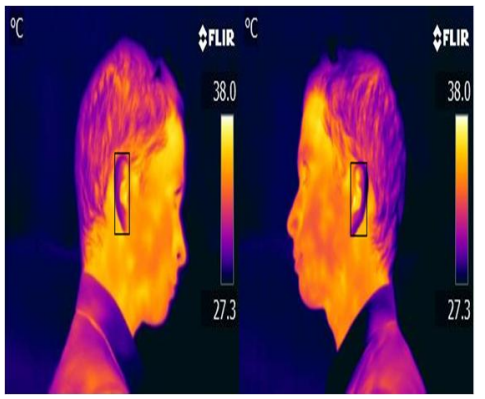

2

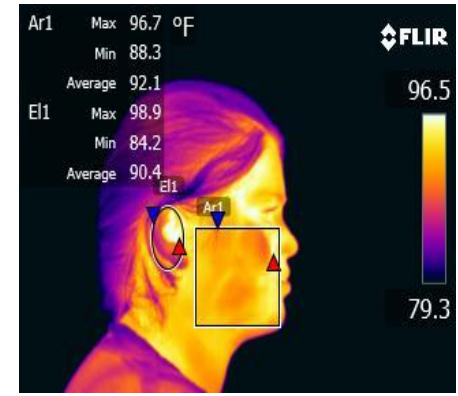

